\title{
Evaluation of Student Performance for Future Perspective in terms of Higher Studies using Fuzzy logic Approach
}

\author{
Gargi Agarwal \\ Dept. of CSE \\ SRMSCET \\ Bareilly, India
}

\author{
Sakshi Gupta \\ Dept. of CSE \\ SRMSCET \\ Bareilly, India
}

\author{
Ashish Agrawal \\ Dept. of CSE \\ SRMSCET \\ Bareilly, India
}

\begin{abstract}
Fuzzy logic has been used for solving various problems of computer science field and many other fields. Fuzzy logic is very useful when it comes to the problem where we need to decide and find the values ranging between 0 and 1 or any other specific range. A student may consider different courses if he/she decides to go for higher studies. Here in this paper authors has used the fuzzy logic to evaluate the correct higher study field for a student. The parameters to consider for evaluation were engineering subject marks which are classified into two fields engineering \& management to analyze the future perspective in terms of higher studies.
\end{abstract}

\section{Keywords}

Fuzzy Logic, Engineering, Future Perspective, Student

\section{INTRODUCTION}

Education system plays an important role for the betterment of the nation. Implementing the fuzzy logic approach on the educational system lead to enhance the evaluation techniques of students so that better results can be obtained. This lead to overall improvement in an educational system that enhances the performance improvement in result evaluation. To evaluate the academic performance of student in various subjects or courses undertaken by student is as to suggest future perspective in terms of higher studies.

In Today Scenario, there is wide Competition and after getting graduate student does not able to an analysis which is right path for him in future that he or she should adopt. On the Basis of fuzzy logic approach the evaluation of student on different parameters can be done on the basis of fuzzy rules and defuzzification technique that help the student to get the clear view what is better for him and what to adopt.

\section{LITERATURE REVIEW}

- In paper [2] the most purpose of this study is that the presentation skills evaluation of pre-service teachers via fuzzy logic. There are two totally different groups during this study. The first one consists of fourteen instructors serving inside the computer Education and information Technology (CEIT) Department of Firat University (FU). This group has provided skilled view in ranking the importance of the matters within the presentation analysis scale (PES) and in forming the rule base that sets ground for the operation of fuzzy logic mechanism. The second group consists of forty one juniors having the operating Systems and Applications Course among the CEIT Department of FU. The scholars during this group build a presentation related to the units of this course,
PES area unit applied on them and also the study is conducted by the information obtained from this scale.

- In paper [5] the authors has propose a new fuzzy logic based performance evaluation technique .During this technique, they consider three parameters attendance, internal marks and external marks that are considered to evaluate students in an IT related Undergraduate course.

- In paper [8] the authors focuses on the fuzzy based approach for evaluation of the student numeric grading without entailing the human judgmental.

- In paper [11] the authors proposes a new performance evaluation technique using fuzzy logic systems. Student performance of laboratory in marmara university Technical Education faculty was applied with fuzzy logic.

\section{PROPOSED APPROACH}

Figure 3.1 shows the flowchart of the proposed approach that basically showing the three phases on which the domains has been processed as- data collection, data refining, applying the fuzzy rules (if-then fuzzy rules) and finally obtaining the result.

In this module of the proposed approach, we are trying to figure out which is the best suitable future perspective for the student on the basis of his academic performance in particular subjects. This helps students to analysis that which future perspective is best. The marks obtained by students in different subjects are divided according to field and then implemented in matlab fuzzy toolbox and on the basis of which evaluation can be made and best future perspective is obtained.

- If a student is having good academic performance in management subjects like economics, psychology, sociology then on the basis of fuzzy if-then rules and linguistic values(very good, good, average, poor, very poor) we can specify what is the linguistic value of student in management.

- If a student is having good academic performance in technical subject like mathematical ability, technical skills, then on the basis of fuzzy if-then rules and linguistic values (very good, good, average, poor, very poor) we can specify what is the linguistic value of student in engineering. 


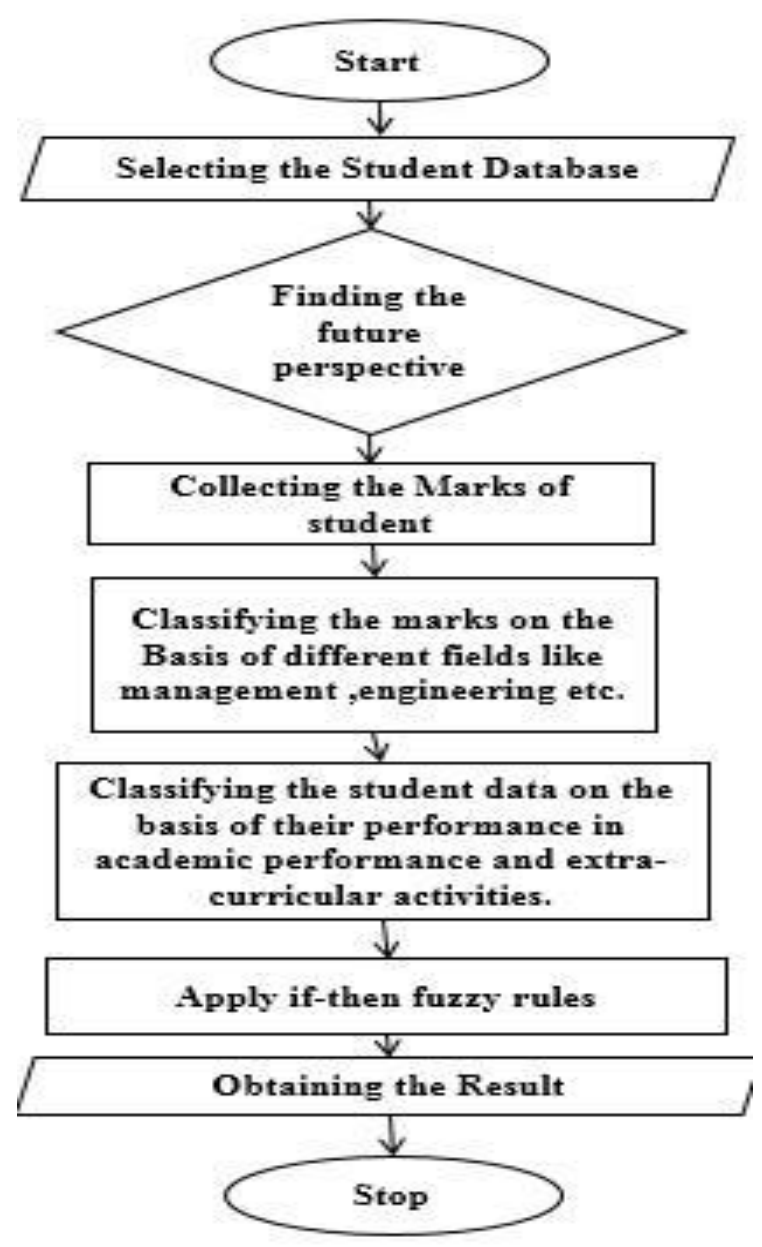

Figure 3.1: Flow Chart of Proposed Approach shows the parameters used for future perspective module of proposed approach.

\section{IMPLEMENTATION}

The implementation of proposed approach is divided three phases that is

- Fuzzy Inference System(FIS)

- Membership function(MF)

- If-then Fuzzy Rules

According the parameters described above there are total six modules which are as follows:

For Management

- Dynamism-Human Values, Psychology, Sociology

- Acumen- Engg. Economics, Industrial Mgmt., Quality Mgmt.

- Management- Dynamism, Acumen

For Engineering

- Mathematical Ability-Quantitative, Reasoning

- Technical Skills- Knowledge of Field, Programming Skills

- Engineering- Mathematical Ability, Technical Skills

Since all the modules have been implemented in the similar way the first module implementation has been shown below

A Mamdani type FIS has been used for building the proposed model for all the module of proposed approach. A view of FIS for first sub- module of future perspective is shown in figure 4.1 .

Finally the outputs obtained by above two fields are compared and on the basis of that we can analysis which is best perspective for students in future. The following figure 3.2

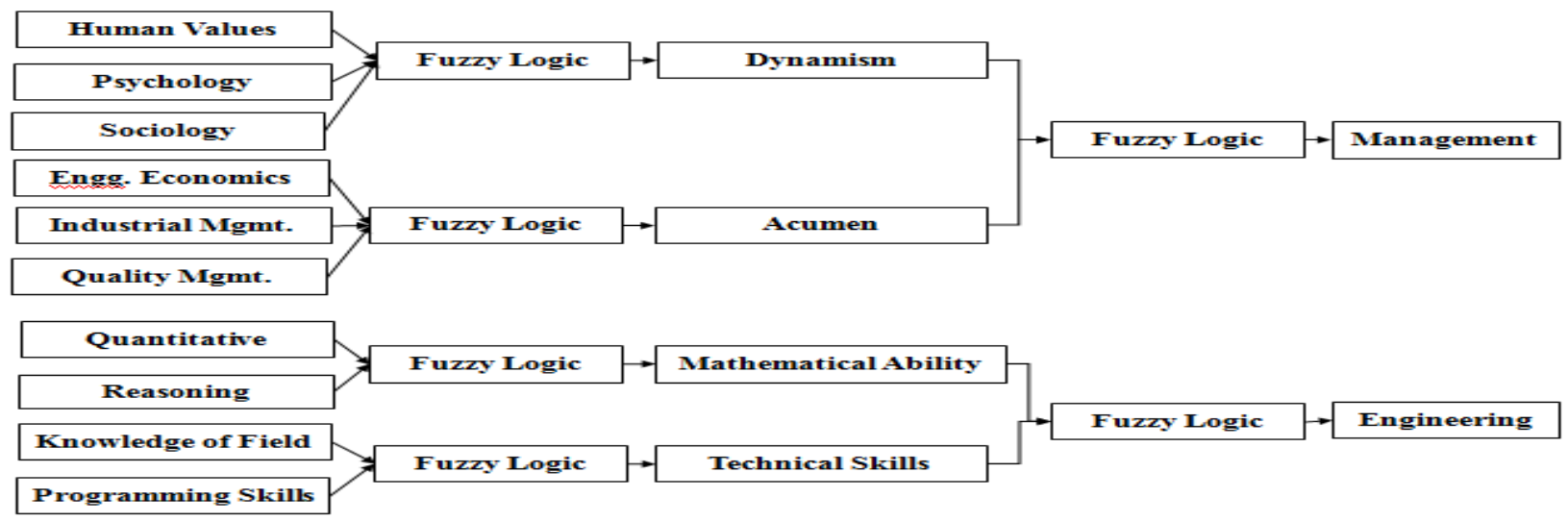

Figure 3.2: Parameters for obtaining future perspective 


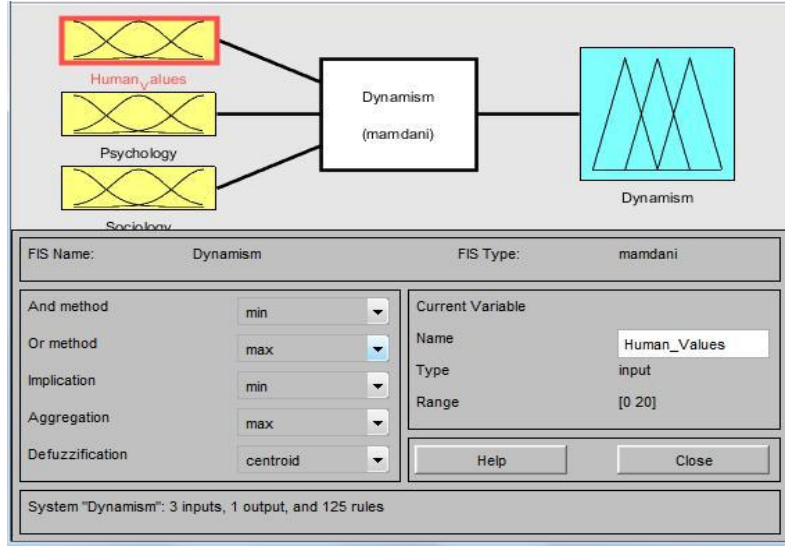

Figure 4.1: FIS Structure of Dynamism Module

In this phase each of the input variable is fuzzified with five linguistic variables (i.e. very poor, poor, average, good and very good) and output variable is fuzzified with five linguistic variable (i.e. very poor, poor, average, good and very good) and given range of [0 20] and [0 1] respectively. A view of input MF's for input attribute i.e. human Values is shown in figure 4.2 and output MF's for output attribute i.e. Dynamism are shown in figure 4.3 .Similarly MF's can be made for other input attributes.

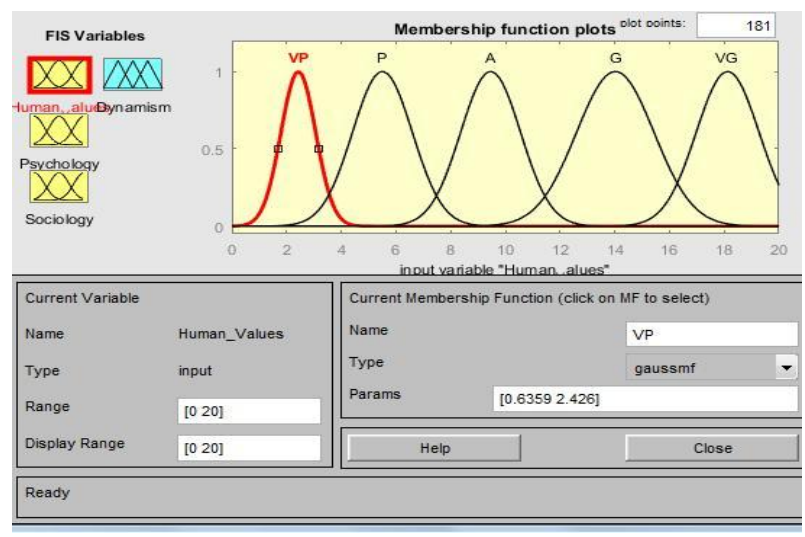

Figure 4.2: MF's of Input human Values

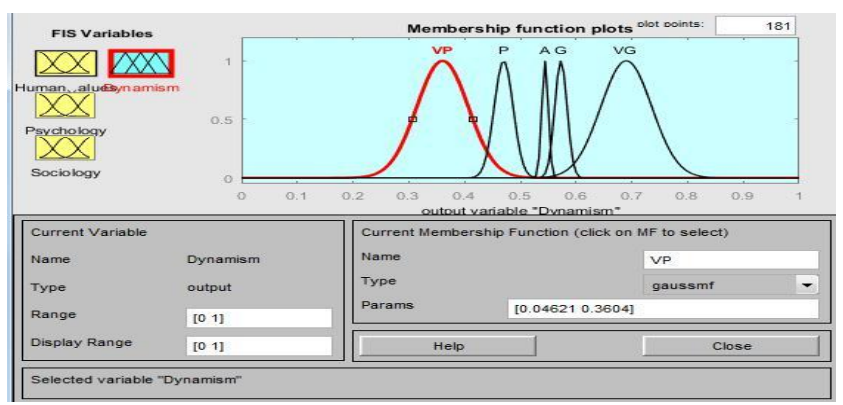

Figure 4.3: MF's of output Dynamism
In this phase a total of 125 if-then fuzzy rules for the FIS has been considered as shown in figure 4.4.The fuzzy rules were built using knowledge and experience of experts, and vary from one expert to another.

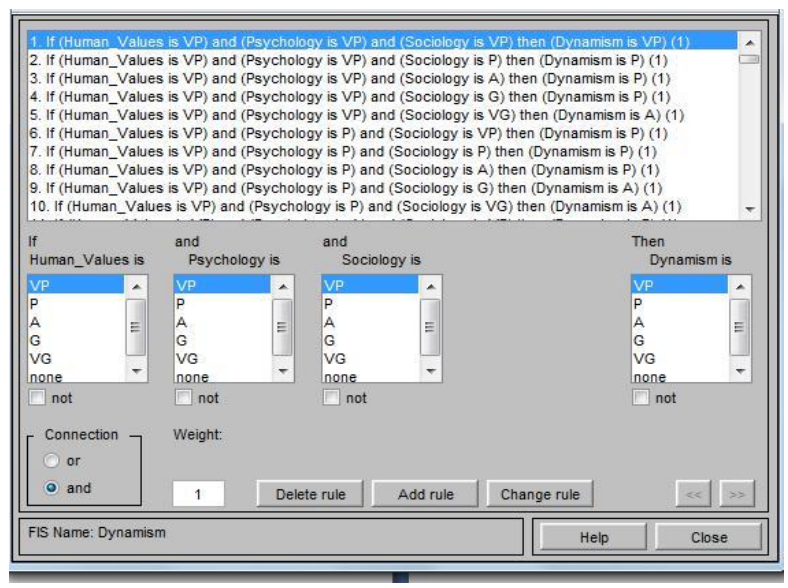

Figure 4.4: Rule Editor for Dynamism

\section{RESULT ANALYSIS}

With the help of fuzzy toolbox we can view the result with the help of two viewer which are as follows:

- $\quad$ Surface viewer

- Rule viewer

For this module of proposed approach entering the marks of first student in different input attribute specified above for management and engineering and the student performance in both the fields has been obtained which is shown in figure 5.1 for management and figure 5.4 for engineering. The values obtained can be shown with the rule viewer and surface viewer in the form of graphs in figure 5.2 and figure 5.3 for management and 5.5 and 5.6 for engineering. In this work the 100 students are tested and the results of final module of 20 students have been obtained which has been shown in table 5.1 for management and table 5.2 for engineering.

\section{FOR MANAGEMENT}

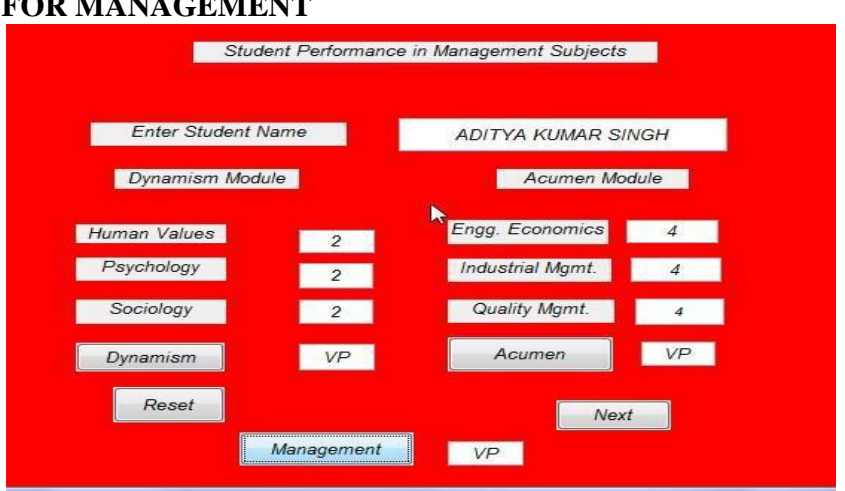

Figure 5.1: First student performance in management 
Table 5.1: 20 student performances in management

\begin{tabular}{|c|c|c|c|c|}
\hline Name of Student & $\begin{array}{c}\text { Dynamism } \\
{\left[\begin{array}{ll}0 & 1\end{array}\right]}\end{array}$ & $\begin{array}{c}\text { Acumen } \\
{\left[\begin{array}{ll}0 & 1\end{array}\right]}\end{array}$ & $\begin{array}{c}\text { Output } \\
{\left[\begin{array}{ll}0 & 1\end{array}\right]}\end{array}$ & $\mathrm{Lv}$ \\
\hline ADITYA KUMAR SINGH & 0.361259 & 0.527629 & 0.546098 & VP \\
\hline ADITYA SINGH & 0.546135 & 0.480144 & 0.563974 & $\mathrm{P}$ \\
\hline AFTAB ALAM & 0.470774 & 0.480534 & 0.551513 & VP \\
\hline AISHWARYA SAXENA & 0.371168 & 0.480143 & 0.532643 & VP \\
\hline AKANKSHA VERMA & 0.46445 & 0.541467 & 0.566233 & $\mathrm{P}$ \\
\hline ANIMESH TIWARI & 0.361259 & 0.480534 & 0.532634 & VP \\
\hline ANIMESH UPADHYAY & 0.360504 & 0.488762 & 0.532677 & VP \\
\hline ANJALI SAXENA & 0.572051 & 0.699796 & 0.669099 & G \\
\hline ANKIT SINGH & 0.371168 & 0.519331 & 0.535751 & VP \\
\hline ANSHIKA GUPTA & 0.571759 & 0.794345 & 0.707366 & $\mathrm{G}$ \\
\hline APOORV AGARWAL & 0.544668 & 0.597835 & 0.614191 & A \\
\hline APOORVA NAYAL & 0.542655 & 0.577728 & 0.611672 & A \\
\hline APURVA AGARWAL & 0.572507 & 0.57928 & 0.665115 & A \\
\hline ARCHIT DUBEY & 0.546423 & 0.595253 & 0.617009 & A \\
\hline ARPIT MEHROTRA & 0.572695 & 0.791413 & 0.707354 & $\bar{G}$ \\
\hline ASHEESH PANDEY & 0.572695 & 0.588922 & 0.665824 & A \\
\hline ASHWANI KUMAR & 0.568728 & 0.583706 & 0.66557 & A \\
\hline ASTHA SRIVASTAVA & 0.568728 & 0.608136 & 0.666276 & G \\
\hline ATUL SINGH & 0.544139 & 0.584968 & 0.613455 & A \\
\hline $\begin{array}{l}\text { AVNISH KUMAR } \\
\text { PANDEY }\end{array}$ & 0.470035 & 0.540726 & 0.56525 & $P$ \\
\hline
\end{tabular}

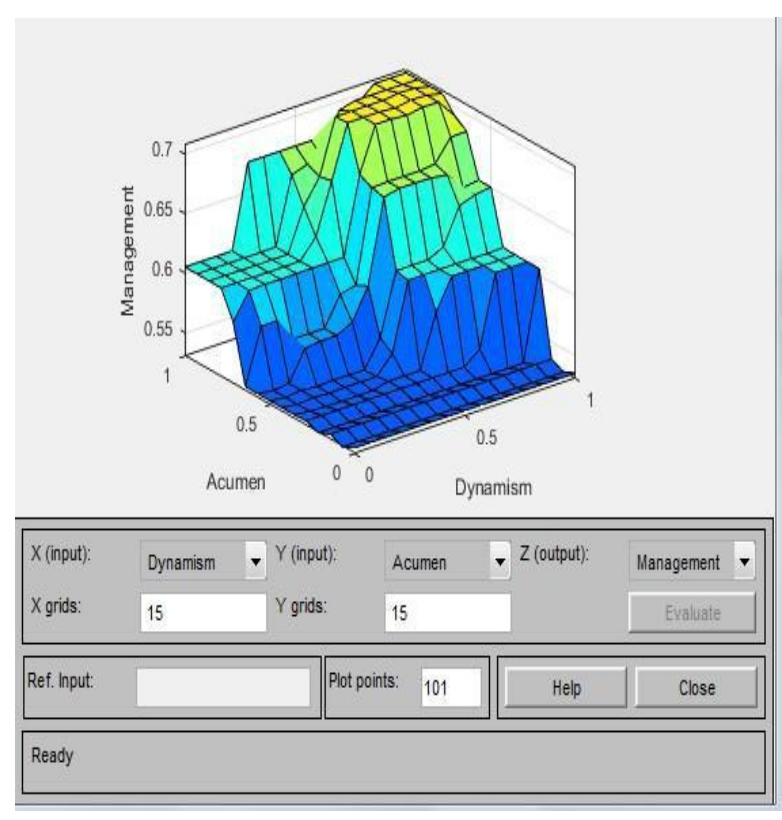

Figure 5.3: Surface Viewer for management module

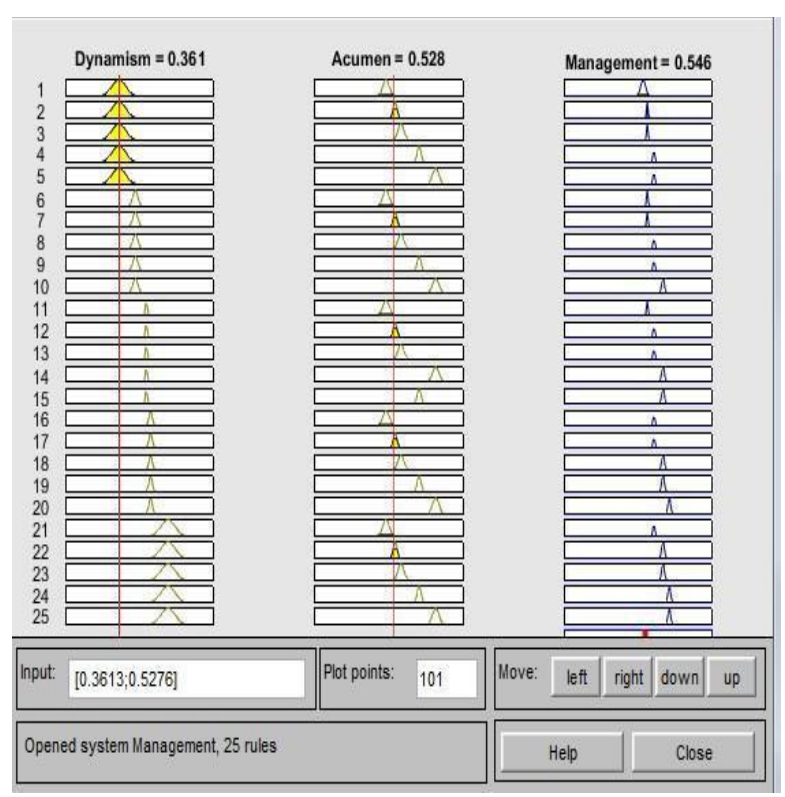

Figure 5.2: Rule viewer for module management for first student 
Table 5.2: 20 student performance in engineering

\begin{tabular}{|c|c|c|c|c|}
\hline Name of Student & $\begin{array}{c}\text { Mathmatical_Ability } \\
{\left[\begin{array}{ll}0 & 1\end{array}\right]}\end{array}$ & $\begin{array}{c}\text { Technical_Skills } \\
{\left[\begin{array}{ll}0 & 1\end{array}\right]}\end{array}$ & $\begin{array}{c}\text { Output } \\
{\left[\begin{array}{ll}0 & 1\end{array}\right]}\end{array}$ & $\mathrm{Lv}$ \\
\hline ADITYA KUMAR SINGH & 0.256339 & 0.412095 & 0.432789 & VP \\
\hline ADITYA SINGH & 0.253726 & 0.543504 & 0.498662 & VP \\
\hline AFTAB ALAM & 0.443069 & 0.643821 & 0.667189 & A \\
\hline AISHWARYA SAXENA & 0.256339 & 0.541356 & 0.498579 & VP \\
\hline AKANKSHA VERMA & 0.480708 & 0.664944 & 0.666692 & A \\
\hline ANIMESH TIWARI & 0.440126 & 0.507632 & 0.504289 & $P$ \\
\hline ANIMESH UPADHYAY & 0.668083 & 0.672258 & 0.708262 & $\mathrm{G}$ \\
\hline ANJALI SAXENA & 0.338216 & 0.412095 & 0.498933 & $\mathrm{VP}$ \\
\hline ANKIT SINGH & 0.700501 & 0.585154 & 0.667126 & $\mathrm{~A}$ \\
\hline ANSHIKA GUPTA & 0.549918 & 0.549448 & 0.580426 & $\mathrm{~A}$ \\
\hline APOORV AGARWAL & 0.685455 & 0.573056 & 0.667343 & $\bar{A}$ \\
\hline APOORVA NAYAL & 0.3343 & 0.550563 & 0.517191 & $\mathrm{P}$ \\
\hline APURVA AGARWAL & 0.700501 & 0.662884 & 0.708427 & $\mathrm{G}$ \\
\hline ARCHIT DUBEY & 0.685455 & 0.545738 & 0.66707 & $\overline{\mathrm{A}}$ \\
\hline ARPIT MEHROTRA & 0.52426 & 0.545638 & 0.584935 & $\mathrm{~A}$ \\
\hline ASHEESH PANDEY & 0.442874 & 0.673416 & 0.66735 & $\overline{\mathrm{A}}$ \\
\hline ASHWANI KUMAR & 0.439514 & 0.585391 & 0.553717 & $\overline{\mathrm{A}}$ \\
\hline ASTHA SRIVASTAVA & 0.53606 & 0.638424 & 0.667479 & $\bar{G}$ \\
\hline ATUL SINGH & 0.442874 & 0.546561 & 0.553638 & $\bar{P}$ \\
\hline $\begin{array}{l}\text { AVNISH KUMAR } \\
\text { PANDEY }\end{array}$ & 0.548384 & 0.667245 & 0.667334 & A \\
\hline
\end{tabular}

\section{FOR ENGINEERING}

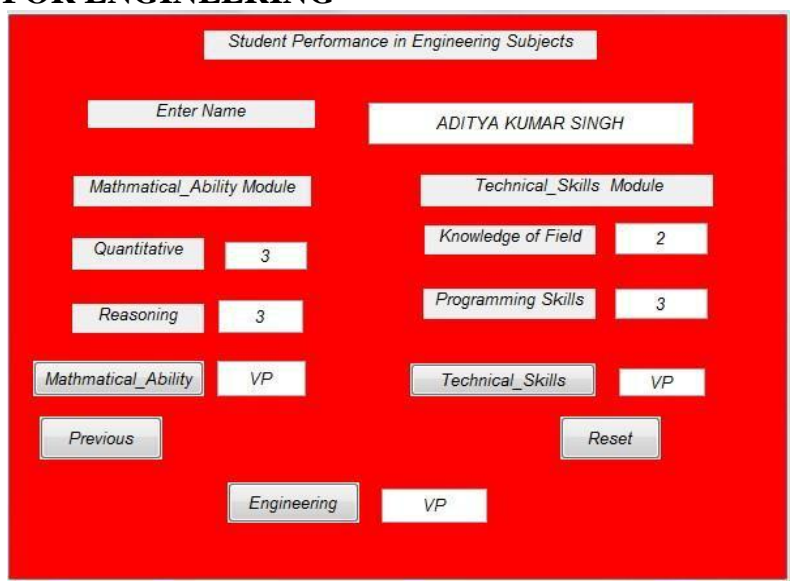

Figure 5.4: First student performance in engineering

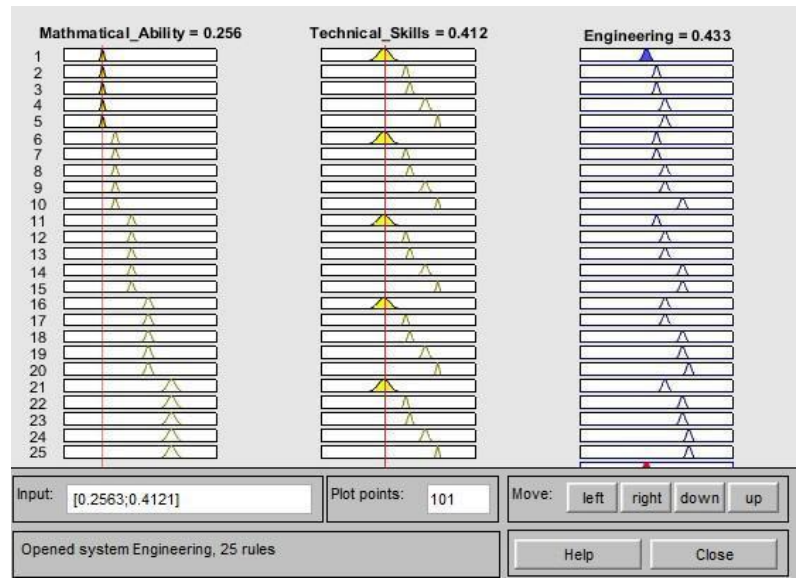

Figure 5.5: Rule viewer for module management for first student 


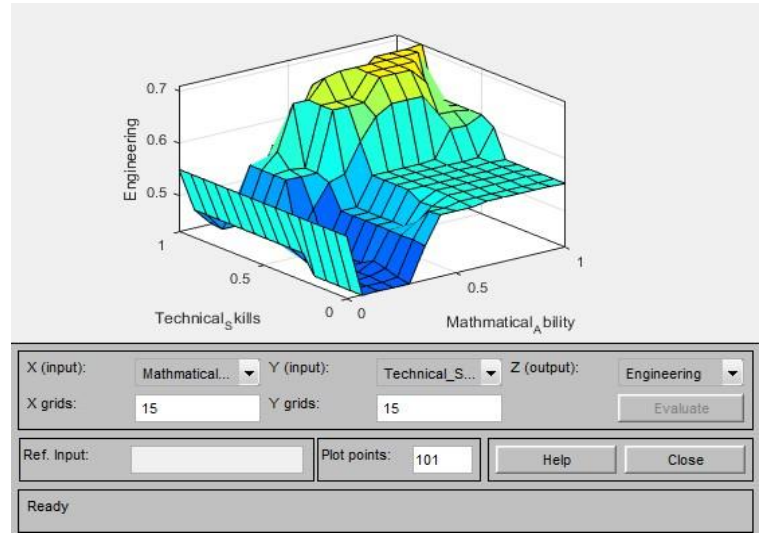

Figure 5.6: Surface Viewer for engineering module

\section{CONCLUSION}

In this domain of study on the basis of student academic performance, the student best future perspective management or engineering can be obtained. These mechanisms of fuzzy logic can be used for the evaluation of different fields on the basis of different parameters which are classified into different linguistic variables to define the range of the membership function.

\section{REFERENCES}

[1] Maria Samarakou, Pantilis Prentakis, 2017.Application of fuzzy logic for assesment of Engineering students. IEEE Global Engineering Education Conference.

[2] Oguzhan Ozdemir,Ahmer Tekin, 2016.Evalution of the Presentation Skills of the pre-service via fuzzy logic.Elsevier.

[3] Alibek Barlybayev, Altynbek Sharipbay, Gulden Ulyukova, Talgat Sabyrov, Bn atyrkh Kuzenbayeva,2016. Student's performance evaluation by fuzzy logic.Elsevier

[4] Meenakshi, Pankaj Nagar,2015.Application of Fuzzy Logic for Evaluation of Academic Performance of Students of Computer Application Course. International Journal for Research in Applied ScienceEngineering Technology
[5] Zehra Yildız, Fevzi Baba, 2014.Evaluation of Student Performance in Laboratory Applications using FuzzyDecision Support System Model'IEEE Global Engineering Education Conference.

[6] Shruti S Jamsandekar, R.R Mudholkar,2013. Performance Evaluation by Fuzzy Inference Technique. International Journal of Soft Computing and Engineering.

[7] SuvarnaPatil, Ayesha Mulla ,R.R. Mudholkar,2012. Best Student Award A FuzzyEvaluation Approach.International Journal of Computer Science and Communication.

[8] RamjeetSinghYadav,Vijendra Pratap Singh, 2011. Modeling Academic Performance Evaluation Using Soft Computing Techniques: A Fuzzy Logic Approach.International Journal on Computer Science and Engineering .

[9] Neetesh Saxena1, Kajal Kaushal Saxena,2010.Fuzzy Logic Based Students Performance Analysis Model for Educational Institutions.IMS Engineering College.

[10] Gokhan Gokmena, Tahir Çetin Akincib, Mehmet Tekta, Nevzat Onatc, Gokhan Kocyigita, Necla Tekta, 2010.Evaluation of student performance in laboratory applications using fuzzy logic. Elesiver.

[11] Ibrahim Saleh, Seong-in Kim,2009. A fuzzy system for evaluating students' learning achievement" Elesiver.

[12] Timothy J.Ross, 2013.Fuzzy logic with engineering applications, Wiley.

[13] S.N. Sivanandam, S.Sumathi, \& S.N. Deepa, 2007. Introduction to fuzzy logic using matlab, Springer.

[14] Guanrong Chen \&Trung Tat Pham, 2001. Introduction to fuzzy logic ,CRC Press.

[15] Andrea Trevino, Introduction to K-Means Clustering', 2016[online].Available:https://www.datascience.com/blog/k-meansclustering.[Accessed:12-Jun-2016]. 